\title{
Individual reproductive success in Norway spruce natural populations depends on growth rate, age and sensitivity to temperature
}

\author{
Camilla Avanzi $\mathbb{B}^{1,2} \cdot$ Katrin Heer $^{3} \cdot$ Ulf Büntgen ${ }^{4,5,6} \cdot$ Mariaceleste Labriola $^{1} \cdot$ Stefano Leonardi ${ }^{2}$. \\ Lars Opgenoorth ${ }^{5,7} \cdot$ Alma Piermattei $^{4} \cdot$ Carlo Urbinati $^{8} \cdot$ Giovanni Giuseppe Vendramin $^{1} \cdot$ Andrea Piotti (i) $^{1}$
}

Received: 1 October 2019 / Revised: 28 February 2020 / Accepted: 28 February 2020 / Published online: 16 March 2020

(c) The Author(s), under exclusive licence to The Genetics Society 2020

\begin{abstract}
Quantifying the individual reproductive success and understanding its determinants is a central issue in evolutionary research for the major consequences that the transmission of genetic variation from parents to offspring has on the adaptive potential of populations. Here, we propose to distil the myriad of information embedded in tree-ring time series into a set of tree-ringbased phenotypic traits to be investigated as potential drivers of reproductive success in forest trees. By using a crossdisciplinary approach that combines parentage analysis and a thorough dendrophenotypic characterisation of putative parents, we assessed sex-specific relationships between such dendrophenotypic traits (i.e., age, growth rate and parameters describing sensitivity to climate and to extreme climatic events) and reproductive success in Norway spruce. We applied a full probability method for reconstructing parent-offspring relationships between 604 seedlings and 518 adult trees sampled within five populations from southern and central Europe. We found that individual female and male reproductive success was positively associated with tree growth rate and age. Female reproductive success was also positively influenced by the correlation between growth and the mean temperature of the previous vegetative season. Overall, our results showed that Norway spruce individuals with the highest fitness are those who are able to keep high-growth rates despite potential growth limitations caused by reproductive costs and climatic limiting conditions. Identifying such functional links between the individual ecophysiological behaviour and its evolutionary gain would increase our understanding on how natural selection shapes the genetic composition of forest tree populations over time.
\end{abstract}

\section{Introduction}

Associate editor: Dario Grattapaglia

Supplementary information The online version of this article (https:// doi.org/10.1038/s41437-020-0305-0) contains supplementary material, which is available to authorized users.

Camilla Avanzi

camilla.avanzi@gmail.com

1 Institute of Biosciences and Bioresources, National Research Council of Italy, Via Madonna del Piano 10, 50019 Sesto Fiorentino (Firenze), Italy

2 Department of Chemistry, Life Sciences and Environmental Sustainability, University of Parma, Parco Area delle Scienze 11/ A, 43124 Parma, Italy

3 Conservation Biology, University of Marburg, Karl-von-FrischStrasse 8, 35043 Marburg, Germany

4 Department of Geography, University of Cambridge, Downing Place, CB2 3EN Cambridge, UK
The question whether long-lived forest trees will thrive or succumb in a changing environment is tightly linked to their local reproductive dynamics (Petit and Hampe 2006) and, in particular, to the consequences that the distribution of

5 Swiss Federal Research Institute, WSL, Zürcherstrasse 111, 8903 Birmensdorf, Switzerland

6 Czech Globe, Global Change Research Institute CAS and Masaryk University, Kotlárská 2, 61137 Brno, Czech Republic

7 Department of Ecology, University of Marburg, Karl-von-FrischStrasse 8, 35043 Marburg, Germany

8 Department of Agricultural, Food and Environmental Sciences, Marche Polytechnic University, Via Brecce Bianche 10, 60131 Ancona, Italy 
individual fitness has on population evolutionary potential (e.g., Moran and Clark 2012; Oddou-Muratorio et al. 2018a). Individual fitness can be expressed in terms of reproductive success, i.e., the actual number of surviving seedlings produced by an individual. The distribution of within-population individual reproductive success ultimately affects next generations' allelic frequencies (González-Martínez et al. 2006), and it is shaped by a complex interaction of local selection, gene flow and genetic drift (Klein et al. 2008; OddouMuratorio et al. 2018a). Understanding which individuals have a higher reproductive success, and why, are crucial issues in evolutionary research (Smouse et al. 1999). In forest tree populations, the distribution of within-population reproductive success is usually skewed, with few individuals that overwhelmingly contribute to the next generation (e.g., Kaufman et al. 1998; Smouse et al. 1999; Moran and Clark 2012; Piotti et al. 2012; Leonarduzzi et al. 2016; Gerzabek et al. 2017). Identifying and modelling the determinants of such unequal reproductive success is still a challenging task (Klein et al. 2008). In fact, reproductive success is the outcome of the complex interplay among individual tree features (e.g., phenotype, microsite conditions), spatial processes (e.g., seed and pollen dispersal, environmental heterogeneity) and timerelated processes (e.g., flowering phenology) (Smouse and Sork 2004; Klein et al. 2008; Oddou-Muratorio et al. 2018a).

The development of adequate genetic and analytical resources has allowed plant biologists to get reliable estimates of lifetime reproductive success, improving fitness estimates solely based on individual basic fecundity (i.e., the number of pollen grains and seeds produced) (Gerzabek et al. 2017; Oddou-Muratorio et al. 2018a). Reproductive success is indeed not a linear function of basic fecundity (Schoen and Stewart 1986), even if the latter is commonly used as a proxy for the former in plants (Younginger et al. 2017). Pre- or post-zygotic selection may decouple male basic fecundity and male reproductive success (Bernasconi 2003). Trade-offs between seed number and quality, as well as the usually high mortality at the seed and seedling stages, may decouple female basic fecundity and female reproductive success (González-Martínez et al. 2006; Moran and Clark 2012). Combining genetic data and modelling approaches to parentage analysis have enabled estimating individual reproductive success while explicitly modelling the effect of its determinants (Oddou-Muratorio et al. 2005; Burczyk et al. 2006; Klein et al. 2008; Moran and Clark 2012) and, simultaneously, accounting for uncertainty in parentage assignments (Jones et al. 2010).

Modelling approaches to parentage analysis estimate, among other parameters, the effect of phenotypic variables on reproductive success (e.g., Burczyk et al. 2006; OddouMuratorio and Klein 2008; Chybicki and Burczyk 2010). This effect is assessed in terms of selection gradient, defined as the slope of the regression of individual reproductive success against measures of phenotypic traits (Morgan and Conner 2001). Among the phenotypic traits potentially linked to individual reproductive success, the effect of tree size is the most frequently investigated (e.g., Schnabel et al. 1998; Kameyama et al. 2001; González-Martínez et al. 2006; Piotti et al. 2009; Leonarduzzi et al. 2016; Chybicki and Oleksa 2018). In a recent review of 170 studies on individual fitness in herbs, shrubs and trees, Younginger et al. (2017) demonstrated that size is a reliable indirect measure of fitness. However, these authors also highlighted that using size to quantify individual fitness may be inappropriate in age-structured natural populations. In fact, tree size is basically the product of the age and the growth rate of a tree (Black et al. 2008; Chybicki and Oleksa 2018), two commingled variables that are not necessarily highly correlated. This shows how carefully selecting the phenotypic variables to be correlated with reproductive success is crucial to not confound the effect of different processes, such as aging and tree productivity. While the combined effect of age and growth rate on reproductive investment has been previously explored in forest trees (e.g., Viglas et al. 2013; Davi et al. 2016), their influence on individual reproductive success has been assessed only in a couple of case studies (González-Martínez et al. 2006; Moran and Clark 2012).

Individual tree age and growth rate can be easily determined with dendrochronological methods, but the study of tree rings offers much more interesting opportunities. Tree rings are natural archives of past environmental information, and their morphological and anatomical properties are influenced by a multitude of environmental and climatic variables (Carrer et al. 2015). By generating multi-decade to multi-century time series of individual annual growth, ringwidth data are an exceptional resource to analyse trees' adaptive responses to climate and environmental stressors (Evans et al. 2018; Heer et al. 2018). An extensive literature review across both gymnosperm and angiosperm tree species showed that most phenotypic traits, at least under controlled environmental conditions, have considerable heritability (Lind et al. 2018) and, therefore, can be linked to the transmission of genetic variation across generations. In particular, moderate to high values of heritability were often found for wood, growth and tree-ring-based traits in conifers (e.g., Hannrup et al. 2004; Martinez Meier et al. 2008; Steffenrem et al. 2009; Chen et al. 2018). Indeed, dendrophenotypic traits (i.e., tree-ring-based phenotypes, sensu Heer et al. 2018) have raised much interest in the recent literature. They have been correlated to population genetic parameters calculated on neutral genetic markers (e.g., King et al. 2013; Latutrie et al. 2015; Babushkina et al. 2016; Housset et al. 2016; Avanzi et al. 2019) and used in genotype-phenotype association studies (Heer et al. 2018; Housset et al. 2018; Trujillo-Moya et al. 2018). So far, only a few studies included single dendrochronological 
traits in models describing parentage relationships (González-Martínez et al. 2006; Moran and Clark 2012; OddouMuratorio et al. 2018b). Although dendrochronological analyses permit to quantitatively describe a wide variety of functional traits (Fonti et al. 2010; Housset et al. 2018), a comprehensive evaluation of the role that different dendrophenotypic traits may play on individual reproductive success of forest trees has never been performed.

The aim of this study was to assess the effects of diverse dendrophenotypic traits on reproductive success within natural populations of Norway spruce (Picea abies (L.) Karst). Stimulated by the approach proposed by Housset et al. (2018), our individual phenotyping was based on three classes of dendrophenotypic traits which described: (i) tree age and individual growth rate, (ii) individual sensitivity to climate and (iii) individual growth responses to past extreme climatic events. Eleven dendrophenotypic variables were calculated for 518 adult trees from five plots. A total of 604 seedlings were collected to estimate the individual reproductive success of the local adult trees. Then, a full probability method for parentage analysis fed by genotypes at biparentally and paternally inherited markers, spatial and phenotypic data was used to assess the influence of dendrophenotypic variables on individual fitness, disentangling potential sex-specific effects on female and male reproductive success. Such relationships were tested by using two different statistical approaches and their outcomes were compared to evaluate the robustness of results.

\section{Materials and methods}

\section{Study areas and data collection}

Five plots from two study areas were sampled. The first study area is located at the southern margin of the species distribution within the Campolino Natural Reserve (northern Apennines, Italy). Three plots were established, named CAML (1475 m a.s.l.), CAME (1615 m a.s.l.) and CAMH (1730 $\mathrm{m}$ a.s.1.) (Table 1). In the second study area, located in the central part of the species distribution within the Bavarian National Park (Bohemian Massif, Germany), two plots were established, named BAVL (730 m a.s.1.) and BAVH (1300 m a.s.l.) (Table 1). An extensive description of plot characteristics was provided by Avanzi et al. (2019). In each plot, all adult trees and a subset of seedlings within a roughly circular area were sampled, collecting a total of 518 and 604 individuals, respectively (Fig. 1 and Table 1). Trees were identified as adults based on the presence of cones in a masting season. Seedlings were collected from different age cohorts (median basal diameter: $4.7 \pm 4.4 \mathrm{~cm}$; median height: $30 \pm 26 \mathrm{~cm}$; Fig. S1) according to local densities. Fresh needles were collected from all 1122 sampled individuals for genetic analyses. An increment core was taken from each adult tree at $1.3 \mathrm{~m}$.

\section{Genetic and dendrochronological characterisation}

The genotypes of both adults and seedlings were scored at 11 unlinked nuclear microsatellite loci (Pa05, Pa28, Pa44: Fluch et al. 2011; SpAGG03: Pfeiffer et al. 1997; WS0092.A19, WS0022.B15, WS0016.O09, WS00111.K13, WS0023.B03: Rungis et al. 2004; EATC1E03, EATC2G05: Scotti et al. 2002) and three chloroplast microsatellite loci (Pt26081, Pt63718, Pt71936: Vendramin et al. 1996). The genetic dataset of adult trees was already presented in Avanzi et al. (2019), where a detailed description of laboratory procedures, the results of the analyses to assess the reliability of the microsatellite marker set as well as the description of the standard dendrochronological methods for processing increment cores were provided. For 36 trees, increment cores were not analysed because of the high number of fractures or
Table 1 Characteristics of the five Picea abies plots.

\begin{tabular}{llllll}
\hline & CAMH & CAME & CAML & BAVH & BAVL \\
\hline Country & Italy & Italy & Italy & Germany & Germany \\
Coordinates $\left({ }^{\circ}\right)$ & $44^{\circ} 06^{\prime}$ & $44^{\circ} 06^{\prime}$ & $44^{\circ} 07^{\prime}$ & $49^{\circ} 05^{\prime} 04^{\prime \prime} \mathrm{N}$ & $49^{\circ} 05^{\prime} 55^{\prime \prime} \mathrm{N}$ \\
& $36^{\prime \prime} \mathrm{N}$ & $47^{\prime \prime} \mathrm{N}$ & $07^{\prime \prime} \mathrm{N}$ & $13^{\circ} 17^{\prime} 06^{\prime \prime} \mathrm{E}$ & $13^{\circ} 13^{\prime} 39^{\prime \prime} \mathrm{E}$ \\
& $10^{\circ} 39^{\prime}$ & $10^{\circ} 39^{\prime}$ & $10^{\circ} 40^{\prime}$ & & \\
Elevation (m a.s.1.) & $44^{\prime \prime} \mathrm{E}$ & $47^{\prime \prime} \mathrm{E}$ & $18^{\prime \prime} \mathrm{E}$ & & \\
Mean temperature $\left({ }^{\circ} \mathrm{C}\right)$ & 1730 & 1615 & 1475 & 1300 & 730 \\
Mean precipitation (mm) & 4.81 & 5.35 & 6.19 & 2.84 & 5.92 \\
Area (ha) & 1937.14 & 1905.99 & 1762.30 & 1140.58 & 933.12 \\
Conspecific density (ind ha $\left.{ }^{-1}\right)$ & 648 & 0.83 & 1.95 & 0.38 & 1.46 \\
Number of adults genotyped & 159 & 127 & 28 & 263 & 68 \\
Number of seedlings & 148 & 105 & 54 & 100 & 100 \\
genotyped & & 100 & 63 & 145 & 148 \\
Number of adults phenotyped & 156 & 102 & 52 & 98 & 74 \\
\hline
\end{tabular}


Fig. 1 Maps of the five Picea abies plots. Adult trees are represented by black dots, while seedlings by grey ones. Spatial positions of all individuals were recorded using both compass and laser distancimeter and a GPS device.

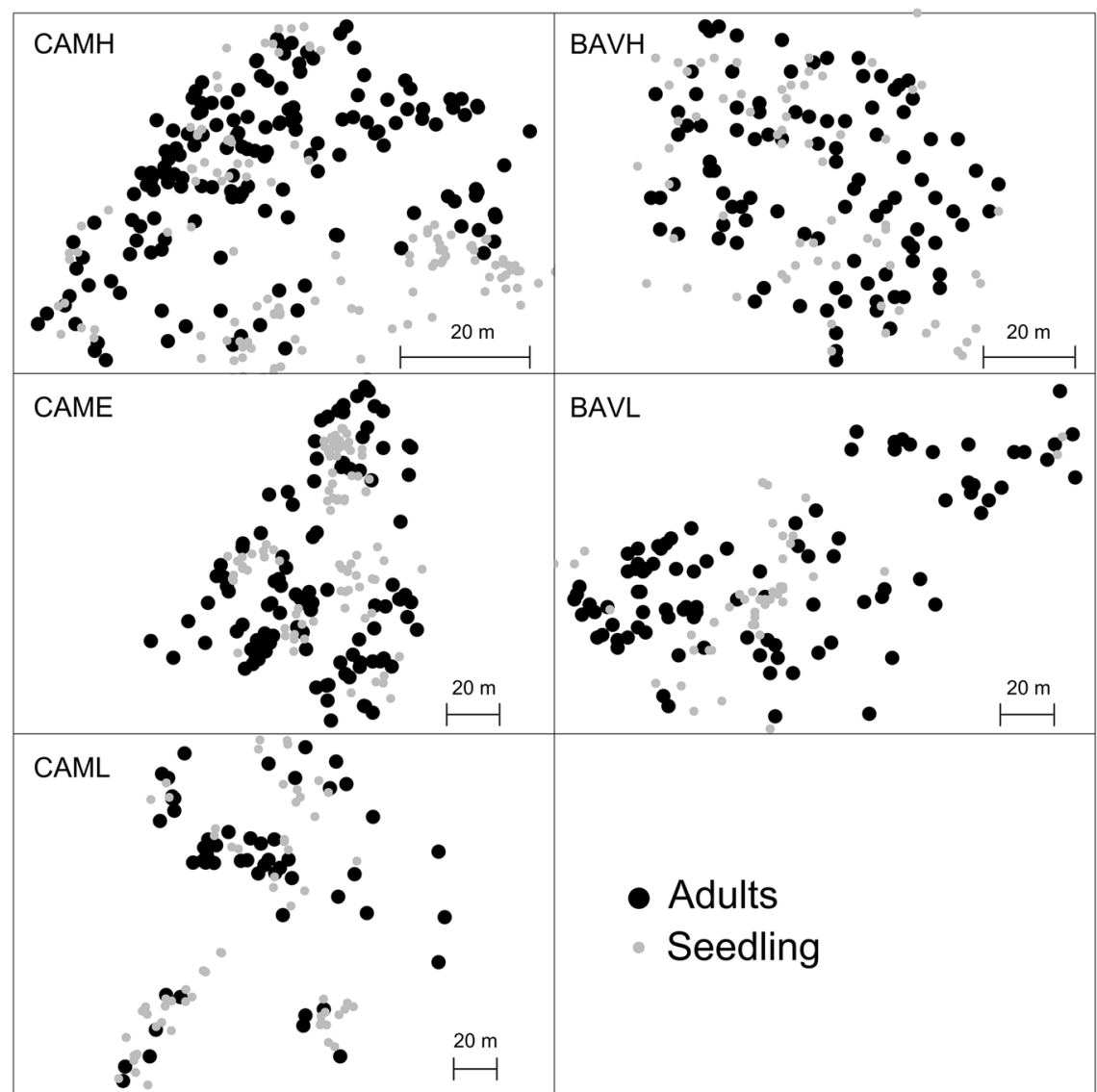

missing segments (Table 1). Cross-dated tree-ring width (TRW) time series were converted to basal area increment (BAI) time series with the function bai.in of the R package dplR (Bunn 2008; R Core Team 2019). BAI better represents the absolute growth rate of stemwood biomass with respect to TRW measures (Hember et al. 2015) and it is less influenced by geometric constraints determined by the age-related increase of stem circumference (Biondi and Qeadan 2008). In addition, TRW time series were standardised by applying a spline function with a $50 \%$ frequency response of 20 years using the program ARSTAN (Cook and Kairiukstis 1990). Standardised tree-ring index (RWI) time series were successively used in the growth-climate correlation analysis.

\section{Dendrophenotypic and spatial variables}

For all adult trees, 11 dendrophenotypic and three spatial variables were measured (Table 2) to assess their effect on individual reproductive success as female and male parents. Dendrophenotypic variables were grouped into three classes of traits which describe (i) individual age and growth rate, (ii) individual sensitivity to climate and (iii) individual growth responses to past extreme climatic events.
Individual tree age was estimated as the count of rings of each tree, while individual growth rate was expressed as the average BAI of the entire series.

Climate sensitivity was expressed in terms of individual growth-climate correlation coefficients. A growth-climate correlation analysis was performed using climatic data of the 1901-2013 period, derived from the CRU TS V.4.0 database (Harris et al. 2014). CRU data of the grid point closest to each study area were corrected for spatial coordinates and elevation of each plot using the software ClimateEU v.4.63 (Hamann et al. 2013). Each RWI time series was correlated against mean temperature and total precipitation of the previous vegetative season (from April to October of the previous year) $\left(\operatorname{Prev}_{\mathrm{T}}, \operatorname{Prev}_{\mathrm{P}}\right)$, the winter season (from November of the previous year to March of the current year) $\left(\mathrm{Wint}_{\mathrm{T}}, \mathrm{Wint}_{\mathrm{P}}\right.$ ) and the current vegetative season (from April to October of the current year) $\left(\operatorname{Curr}_{\mathrm{T}}, \operatorname{Curr}_{\mathrm{P}}\right)$.

Growth responses to past extreme climatic events were expressed in terms of resistance, recovery and resilience (Lloret et al. 2011). In this framework, resistance (Rt) measures tree growth reduction during the extreme episode; recovery $(\mathrm{Rc})$ measures tree growth increase after the extreme episode; resilience (Rs) measures the capacity of the tree to 


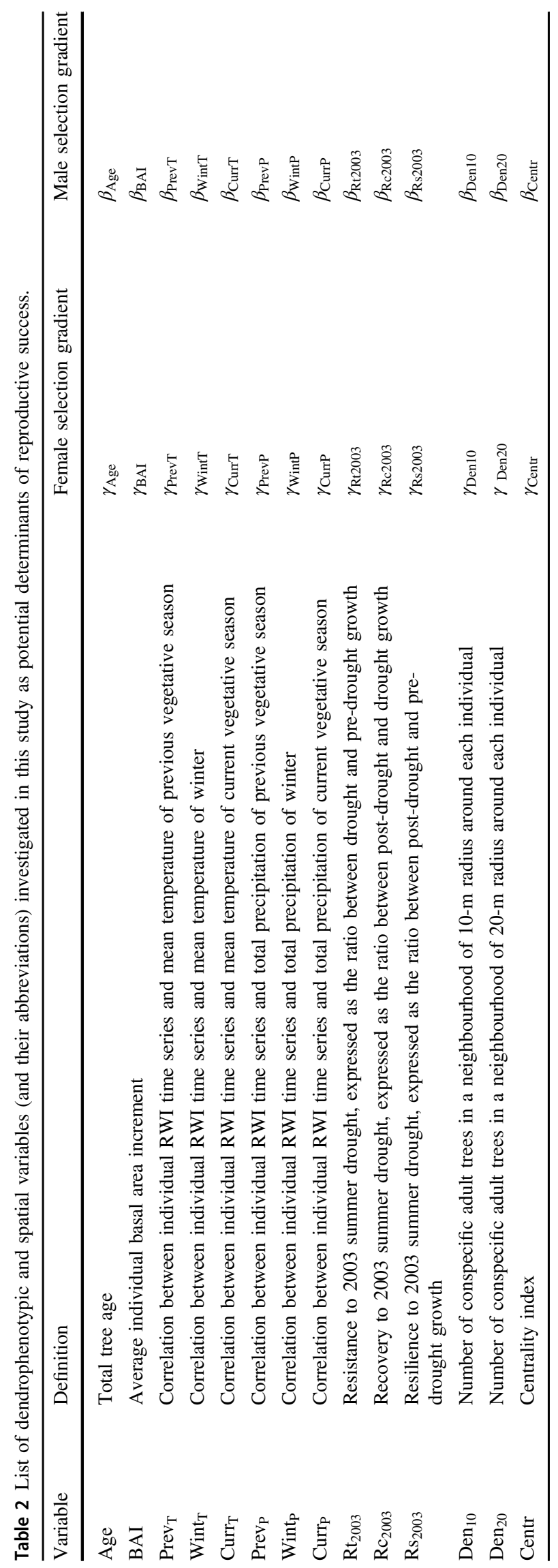

reach pre-episode growth levels. As spruce is highly influenced by the summer water deficit of the current growing season (Lebourgeois 2007), all these indices were calculated on BAI time series for year $2003\left(\mathrm{Rt}_{2003}, \mathrm{Rc}_{2003}, \mathrm{Rs}_{2003}\right)$, when Europe experienced one of the hottest and driest summer over the last centuries (Fink et al. 2004). Such extreme climatic conditions occurred also in our study areas, where summer temperatures were, on average, $3{ }^{\circ} \mathrm{C}$ above the mean values calculated for the 1901-2013 period, while precipitations were 37\% below (Fig. S2a, b, respectively). All indices were calculated with the res.comp function of the $\mathrm{R}$ package pointRes (van der Maaten-Theunissen et al. 2013) using a 'reference period' of four years before and after the 2003 extreme climatic event (Fig. S2c).

In addition, three spatial variables often used as covariates of reproductive success in parentage-based studies were calculated for each adult tree (Table 2). Conspecific local density was calculated as the number of adult trees found in a 10- and 20-m radius around each adult individual ( $\operatorname{Den}_{10}$ and $\operatorname{Den}_{20}$, respectively). A centrality index (Centr) was calculated to take into account a potential 'edge-effect', i.e., trees on borders may exhibit lower densities because individuals outside the plot were not sampled. Centr was expressed as the shortest distance between each tree and the borders of the polygon representing the convex hull (drawn using chull function in $\mathrm{R}$ ) of the set of tree locations in each plot.

\section{Reconstruction of seedling genealogies and estimation of individual reproductive success}

The seedling neighbourhood model (Burczyk et al. 2006), as implemented in the NM $\pi$ software (Chybicki 2018), was used to reconstruct seedling genealogies (i.e., their most likely mother and father, comprising unsampled individuals). Seed and pollen immigration rates, self-pollination rate, genotyping errors and seed and pollen dispersal kernel parameters were simultaneously estimated while accounting for both multilocus genotypes and spatial positions of adults and seedlings. The dispersal process was modelled through an exponentialpower kernel. The gender ("femaleness") of the putative parents was set to 0.5 as Norway spruce is a hermaphrodite species. Analyses were performed on the entire dataset, setting the neighbourhood size to $215 \mathrm{~m}$ (i.e., the maximum within-plot pairwise spatial distance between individuals) to model the dispersal process at the neighbourhood level. Seed and pollen immigration rates, genotyping errors, selfpollination rate and seed and pollen dispersal kernel parameters were estimated following the step-wise approach described in the NM $\pi$ manual (Chybicki 2018). The resulting most likely genealogies for each seedling were used to calculate female and male individual reproductive success, expressed as the sum of gametes sired by each tree through its maternal and paternal function, respectively. 


\section{The effect of dendrophenotypic and spatial variables on individual reproductive success}

Two different approaches were used to assess the effect of dendrophenotypic and spatial variables on female and male individual reproductive success.

In the first approach, the effect of covariates on reproductive success was assessed by including standardised dendrophenotypic and spatial variables as selection gradients in the neighbourhood model. Since the model did not converge including all selection gradients $(14 \gamma$ parameters and $14 \beta$ parameters for female and male effect, respectively; Table 2), we used an alternative strategy to the classical backward procedure based on excluding the least significant variable and refitting the model. A first series of 28 models was run including only one selection gradient at a time. This step aimed at ranking female and male selection gradients based on their fits in terms of the Akaike information criterion of the model. Based on such ranking, a second and a third series of models were run adding sequentially female and male selection gradients, respectively. Each selection gradient was retained in the model when it improved the model fitting. Model comparison was made according to likelihood ratio test, based on the likelihoods of the competing models (Chybicki 2018). A model including all the retained female and male selection gradients was run to obtain final parameter estimates.

In the second approach, the effect of covariates on reproductive success was assessed a posteriori through classical statistical modelling. The estimates of female and male individual reproductive success ( $\psi$ and $\varphi$, respectively), obtained by running the neighbourhood model without selection gradients, were regressed against dendrophenotypic and spatial variables. Such modelling approach permitted to evaluate the effect of each single variable ceteris paribus (i.e., isolating its relative contribution while holding constant the effect of the other variables). In order to properly account for overdispersion, a GLM with a negative binomial error distribution was fitted. The testZeroInflation function of the R package DHARMa (Hartig 2019) was used to compare the observed number of zeros with those expected from 1000 simulations of the model, and it allowed us to exclude zero inflation in the dataset.

The starting model was the following:

$$
\begin{aligned}
& \psi, \varphi \sim \text { Plot }+ \text { Age }+A g e^{2}+B A I+B A I^{2}+R t_{2003}+ \\
& R c_{2003}+R s_{2003}+\text { Prev }_{T}+\text { Wint }_{T}+\text { Curr }_{T}+\text { Prev }_{P}+, \\
& \text { Wint }_{P}+\text { Curr }_{P}+\text { Den }_{10}+\text { Den }_{20}+\text { Centr }+\varepsilon
\end{aligned}
$$

where the site (Plot) was considered as a categorical variable, whereas all the other variables as quantitative covariates. Quadratic terms for both tree age $\left(\mathrm{Age}^{2}\right)$ and average $\mathrm{BAI}\left(\mathrm{BAI}^{2}\right)$ were included in the model to test for non-linear effect of these variables on reproductive success. All explanatory variables were centred and scaled. Analyses were performed by using the glm.nb function of the $\mathrm{R}$ package MASS (Venables and Ripley 2002). To avoid collinearity problems, variance inflation index (VIF) was calculated for each variable of (1) using the R package car (Fox and Weisberg 2011). The variable with the highest VIF was sequentially dropped from the model until all variables had VIF values <3 (Zuur et al. 2010). This procedure led to the exclusion of $\mathrm{Rs}_{2003}$ and $\mathrm{Den}_{20}$ from both models of female and male reproductive success. After this first step, model averaging with Bayesian information criterion (BIC) was performed to account for model uncertainty and to reduce parameter estimation bias (Burnham and Anderson 2002) through the R package MuMIn (Barton 2018). Alternative models with all possible combinations of the considered variables were built using the dredge function. The site variable (Plot) was arbitrarily forced to be always included in each alternative model. Model comparison was based on BIC, by selecting models with $\Delta_{\text {BIC }}<10$ (Aho et al. 2014). On this subset of models, model averaging based on model weights was performed using the model.avg function to obtain averaged standardised conditional coefficients.

Both methods have advantages and drawbacks. Briefly, the neighbourhood model has the major advantage to simultaneously estimate selection gradients together with all other model parameters (Burczyk et al. 2006), thus limiting the propagation of error possibly linked to a two-step analysis. On the other hand, as the neighbourhood model is based on a maximum-likelihood estimation of parameters, it might fail to converge when the number of parameters is too large with respect to available data. Moreover, the soft-max regression approach implemented in $\mathrm{NM} \pi$ is generally efficient to infer the effect of covariates on reproductive success (Chybicki 2018) but less flexible than an ad-hoc built model. For example, modelling the effect of phenotypic traits on reproductive success through a GLM would allow to better describe error distributions, to implement model averaging strategies to reach more robust parameter estimates, and to increase model complexity when this is profitable (e.g., as in multi-site comparisons or in experiments based on a factorial design).

\section{Results}

\section{Dendrophenotypic traits}

The five plots were characterised by different age structures (Fig. S3a). In CAMH and CAML, $81 \%$ and $64 \%$ of trees were $\leq 60$ years, with a median age of 42 and 53 years, 
respectively. In the other three plots, the percentage of trees $<60$ years was markedly lower (CAME: $16 \%$; BAVH: $3 \%$; BAVL: $20 \%$ ) and the median age $\geq 100$. The distributions of individual average BAI were similar among Italian plots. The lowest average BAI was recorded in BAVH $\left(766 \mathrm{~mm}^{2}\right)$, while BAVL was characterised by the highest growth rate $\left(2643 \mathrm{~mm}^{2}\right)$ and the largest standard deviation (Fig. S3b).

Growth-climate correlations were globally low, with mean Pearson's correlation coefficients of 0.014 and 0.018 for temperature and precipitation responses, respectively (Fig. S3c-h). Correlation values showed a wide range of individual growth responses to temperature and precipitation. For instance, individual growth responses to precipitation of the current vegetative season ranged from -0.774 to 0.552 .

Large inter-individual variation was also associated to the indices describing growth responses to the 2003 summer drought (Fig. S3i-k). Almost all trees from the German plots exhibited a growth decline $(89 \%$ and $91 \%$ of trees with $\mathrm{Rt}<1$ in BAVH and BAVL, respectively) while trees from the Italian plots were generally less affected by the 2003 summer drought $(54 \%, 61 \%$ and $67 \%$ of trees with Rt $<1$ in CAME, CAML and CAMH, respectively) (Fig. S3i and Table S1). In the four years following the 2003 summer drought, trees from the German plots grew less, on average, with respect to the pre-drought period (Supplementary Fig. S3k and Supplementary Table S1).

\section{Individual reproductive success}

A local mother tree was assigned to 296 out of 604 seedlings (49\%), while 79 seedlings $(13 \%)$ were assigned to a local father. Seedlings with both parents, one parent and no parents assigned within the plot were 79 (13\%), 217 (36\%) and $308(51 \%)$, respectively. Within-plot distributions of individual reproductive success were highly skewed (Fig. S4). The percentages of trees producing $>2$ gametes were $5 \%$ in CAMH and BAVH, 9\% in CAML and 13\% in CAME and BAVL. A posteriori probabilities of the first most likely genealogy were generally much higher than those of the second most likely genealogy (Fig. S5), indicating the robustness of the marker set used for reconstructing genealogies. Such robustness was expected as the exclusion probabilities jointly calculated on nuclear and cytoplasmic markers using the software FAMOZ (Gerber et al. 2003) were 0.9997 for single parents and 0.9999 for parent pairs.

\section{Determinants of female and male individual reproductive success}

The neighbourhood model parameters estimated without selection gradients were highly consistent with those of the model run including selection gradients and, therefore, only the latter were presented (Table S2). Seed and pollen immigration rates were $0.461( \pm 0.025)$ and $0.755( \pm 0.029)$, respectively. Estimates of genotyping error rates were low, ranging from 0 to 0.085 , with an average value of 0.040 . Self-pollination rate did not improve the likelihood of the model and, therefore, it was treated as a fixed parameter by using the default value in $\mathrm{NM} \pi(s=0.01)$. The inverse of the average seed dispersal distance $\left(1 / \delta_{\mathrm{s}}\right)$ was 0.026 $( \pm 0.002)$ indicating an average seed dispersal distance equal to $38.5 \mathrm{~m}\left(\mathrm{CI}_{95 \%} 33.3-45.4 \mathrm{~m}\right)$. On the other hand, the inverse of average pollen dispersal distance $\left(1 / \delta_{\mathrm{p}}\right)$ was not significantly different from 0 and its inclusion did not improve the likelihood of the model. Thus, it was treated as a fixed parameter by using the default value in $\mathrm{NM} \pi\left(1 / \delta_{\mathrm{p}}=\right.$ $0)$. Adding the shape parameters of both seed and pollen dispersal functions did not improve the likelihood of the model as well and, therefore, they were treated as fixed parameters by using the default value in $\mathrm{NM} \pi\left(b_{\mathrm{s}}=b_{\mathrm{p}}=1\right)$. This led us to simplify the dispersal model from an exponential power to an exponential function. The oversimplification of the pollen dispersal function might be due to the relatively low number of local dispersal events detected, which is a known drawback in modelling reproductive success in highly outcrossing species (see GonzálezMartínez et al. 2006).

An overview of the effects of all the investigated dendrophenotypic traits on reproductive success was provided in Fig. 2. In the first approach used to assess the effect of dendrophenotypic traits on individual reproductive success, which was based on estimating selection gradients within the neighbourhood model, female reproductive success was positively influenced by age $\left(\gamma_{\mathrm{Age}}=0.312 \pm 0.098\right)$, average BAI $\left(\gamma_{\mathrm{BAI}}=0.231 \pm 0.054\right)$ and growth-climate correlation with the mean temperature of the previous vegetative season $\left(\gamma_{\text {PrevT }}=0.207 \pm 0.079\right)$, while it was negatively influenced by resilience $\left(\gamma_{\mathrm{Rs} 2003}=-0.364 \pm 0.111\right)$ (Table 3 and Fig. 2). Male reproductive success was positively influenced by age $\left(\beta_{\text {Age }}=0.792 \pm 0.236\right)$, growth-climate correlation with the precipitation of the previous vegetative season $\left(\beta_{\text {PrevP }}=0.637 \pm\right.$ $0.200)$ and average BAI $\left(\beta_{\mathrm{BAI}}=0.416 \pm 0.127\right)$ (Table 3$)$.

In the second approach used, which was based on modelling the effect of covariates on reproductive success through a GLM, female individual reproductive success was positively associated with average BAI $(B A I=0.238)$ and growth-climate correlation with the mean temperature of the previous vegetative season $\left(\operatorname{Prev}_{T}=0.212\right)$ while it was negatively associated to the growth-climate correlation with winter precipitation ( Wint $\left._{P}=-0.271\right)$ (Fig. 2, Fig. S6 and Table 4). In addition, female reproductive success had a downward quadratic dependency on age (Age $=0.615$, $\left.A g e^{2}=-0.319\right)$ which reached its maximum at $\sim 160$ years (Fig. S6a). Male individual reproductive success was 


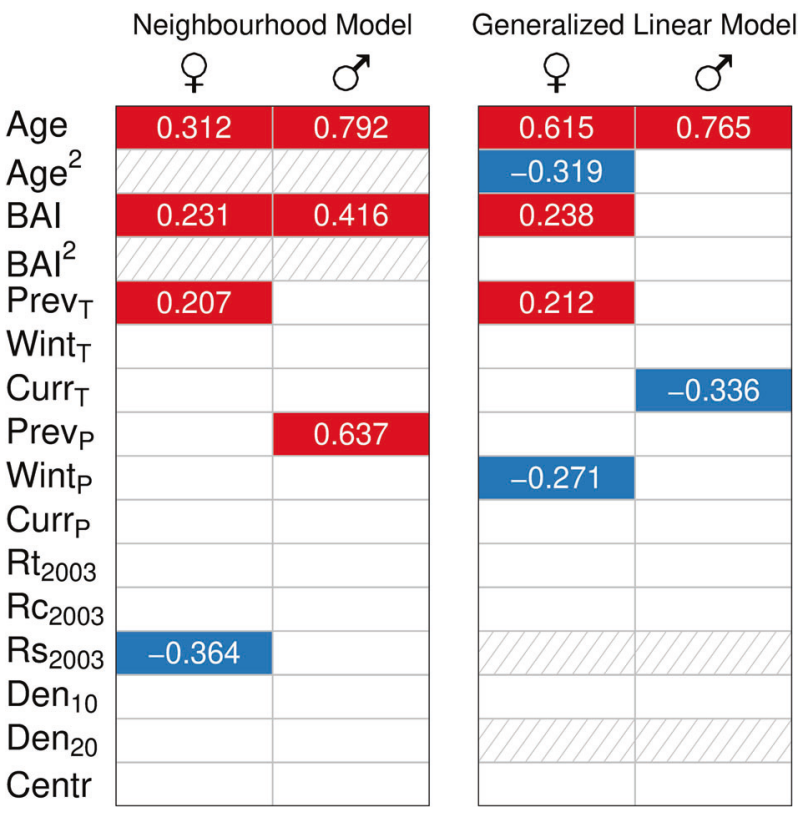

Fig. 2 Comparison of the results of the two methods applied to assess the effect of dendrophenotypic and spatial variables on both female and male reproductive success. Red boxes indicate that the variable has a significant and positive effect, while blue boxes that it has a significant and negative effect. The magnitude of such effect is reported inside the box, and it is expressed in terms of selection gradients for the neighbourhood model and averaged coefficients for the generalised linear model (GLM). All reported coefficients are expressed in standard deviation units, so that they are comparable within method. Striped boxes indicate that the variable has not been included as a selection gradient in the neighbourhood model or that it has been removed from the GLM because of collinearity (VIF $>3$; Zuur et al. 2010).

Table 3 Selection gradients expressed as the slopes of the regression of phenotypic traits against female ( $\gamma$ parameters) and male $(\beta$ parameters) individual reproductive success.

\begin{tabular}{lclc}
\hline Parameter & Estimate & s.e. & $95 \%$ CI \\
\hline$\gamma_{\text {Age }}$ & 0.312 & 0.098 & $0.119,0.505$ \\
$\gamma_{\text {BAI }}$ & 0.231 & 0.054 & $0.126,0.337$ \\
$\gamma_{\text {Rs2003 }}$ & -0.364 & 0.111 & $-0.582,-0.146$ \\
$\gamma_{\text {PrevT }}$ & 0.207 & 0.079 & $0.052,0.363$ \\
$\beta_{\text {Age }}$ & 0.792 & 0.236 & $0.329,1.255$ \\
$\beta_{\text {BAI }}$ & 0.416 & 0.127 & $0.166,0.665$ \\
$\beta_{\text {PrevP }}$ & 0.637 & 0.200 & $0.245,1.028$ \\
\hline
\end{tabular}

Only selection gradients that were statistically significant in the final run of the neighbourhood model were reported.

positively associated to age $($ Age $=0.765)$, while it was negatively associated to growth-climate correlation with the mean temperature of the current vegetative season $\left(\mathrm{Curr}_{T}=\right.$ -0.336). (Fig S6 and Table 4). BAI had only a marginal effect on male reproductive success $(B A I=0.265 ; P=$ 0.106). The site factor (Plot) was statistically significant in both models, indicating differences among plots in the mean female and male individual reproductive success (Table 4). Including the site factor in the models allowed us to explicitly account for such differences while estimating the effect of the other covariates. Almost identical results were obtained when GLM analyses were run by using dendrophenotypic and spatial variables standardised at the plot level (Fig. S7), indicating that differences among plots were correctly taken into account in our modelling approach.

\section{Discussion}

\section{Influence of growth rate and age on reproductive success}

Reproduction is costly and tends to reduce vegetative growth in plants, at least for a limited period of time (e.g., Obeso 2002; Petit and Hampe 2006). For example, masting years were found to be associated with both reduced diameter (Eklund 1957; Pukkala 1987) and tree ring width (Eis et al. 1965) in conifers. By analysing $>6000$ silver fir trees at the individual level, Davi et al. (2016) found that a higher cone production was associated with a lower radial growth rates in the previous years. From an evolutionary point of view, it is of the utmost importance to understand how different individuals cope with such reproductive costs not only in single reproductive seasons but throughout their lifetime to maximise their reproductive success (Barringer et al. 2013). Our understanding of the link between individual growth and reproductive success is still limited and, to date, only a few studies have collected the genetic and dendrochronological data required to study this relationship through parentage analysis (González-Martínez et al. 2006, Moran and Clark 2012; Oddou-Muratorio et al. 2018b). A hump-shaped relationship between growth rate and female reproductive success was observed in red oaks by Moran and Clark (2012), leading these authors to hypothesise the existence of a trade-off between growth rate and reproductive success. A trade-off between growth and reproductive investment has often been found in plants (e.g., Obeso 2002). However, in tree species, significant tradeoffs may not be observed due to their capability to store and mobilise resources as a buffer against energy depletion in years of high reproductive output and/or stressful environmental conditions (Barringer et al. 2013). Nevertheless, most studies on reproductive costs are based on limited time periods while uncovering the link between growth and reproductive dynamics in trees would require gathering long-lasting temporal data spanning multiple reproductive events (Barringer et al. 2013; Hacket-Pain et al. 2019).

Our findings, based on the reconstruction of the reproductive dynamics of 518 Norway spruce trees over multiple reproductive events, indicated no evidence of a possible 
Table 4 Averaged standardised coefficients predicting the effect of dendrophenotypic and spatial variables on both female and male individual reproductive success.

\begin{tabular}{|c|c|c|c|c|c|c|c|c|}
\hline \multirow[b]{2}{*}{ Variable } & \multicolumn{4}{|c|}{ Female reproductive success } & \multicolumn{4}{|c|}{ Male reproductive success } \\
\hline & Estimate & s.e. & $Z$ & $P(>|\mathrm{z}|)$ & Estimate & s.e. & $Z$ & $P(>|z|)$ \\
\hline Intercept & -0.942 & 0.364 & 2.586 & 0.010 & -3.974 & 0.720 & 5.508 & $<0.001$ \\
\hline Age & 0.615 & 0.197 & 3.120 & 0.001 & 0.765 & 0.241 & 3.166 & 0.001 \\
\hline $\mathrm{Age}^{2}$ & -0.319 & 0.124 & 2.573 & 0.010 & -0.212 & 0.208 & 1.020 & 0.308 \\
\hline BAI & 0.238 & 0.101 & 2.353 & 0.019 & 0.265 & 0.163 & 1.618 & 0.106 \\
\hline $\mathrm{BAI}^{2}$ & 0.028 & 0.025 & 1.099 & 0.271 & 0.004 & 0.054 & 0.065 & 0.948 \\
\hline $\operatorname{Prev}_{\mathrm{T}}$ & 0.212 & 0.099 & 2.127 & 0.033 & -0.161 & 0.162 & 0.987 & 0.323 \\
\hline Wint $_{\mathrm{T}}$ & -0.112 & 0.117 & 0.956 & 0.339 & 0.233 & 0.180 & 1.294 & 0.195 \\
\hline $\operatorname{Curr}_{\mathrm{T}}$ & 0.116 & 0.112 & 1.028 & 0.304 & -0.336 & 0.157 & 2.138 & 0.033 \\
\hline $\operatorname{Prev}_{P}$ & 0.034 & 0.123 & 0.280 & 0.779 & 0.171 & 0.179 & 0.955 & 0.340 \\
\hline Wint $_{P}$ & -0.271 & 0.108 & 2.509 & 0.012 & 0.030 & 0.171 & 0.175 & 0.861 \\
\hline Curr $_{P}$ & 0.135 & 0.114 & 1.187 & 0.235 & -0.042 & 0.175 & 0.243 & 0.808 \\
\hline $\mathrm{Rt}_{2003}$ & -0.104 & 0.125 & 0.835 & 0.404 & 0.046 & 0.155 & 0.296 & 0.767 \\
\hline $\mathrm{Rc}_{2003}$ & -0.010 & 0.098 & 0.098 & 0.922 & -0.147 & 0.195 & 0.752 & 0.452 \\
\hline \multicolumn{9}{|l|}{$\mathrm{Rs}_{2003}$} \\
\hline $\operatorname{Den}_{10}$ & -0.159 & 0.171 & 0.924 & 0.355 & 0.306 & 0.230 & 1.330 & 0.184 \\
\hline \multicolumn{9}{|l|}{$\operatorname{Den}_{20}$} \\
\hline Centr & 0.099 & 0.103 & 0.965 & 0.334 & 0.090 & 0.166 & 0.542 & 0.588 \\
\hline Plot $_{\text {CAMH }}$ & 0.447 & 0.471 & 0.946 & 0.344 & 2.517 & 0.981 & 2.561 & 0.010 \\
\hline Plot $_{\text {CAME }}$ & 0.555 & 0.363 & 1.525 & 0.127 & 2.472 & 0.673 & 3.667 & $<0.001$ \\
\hline Plot $_{\text {CAML }}$ & 0.663 & 0.474 & 1.398 & 0.162 & 1.851 & 0.954 & 1.936 & 0.053 \\
\hline Plot $_{\text {BAVL }}$ & 0.422 & 0.456 & 0.923 & 0.356 & 1.839 & 0.726 & 2.527 & 0.012 \\
\hline
\end{tabular}

Coefficients are in boldface if the $95 \%$ confidence interval $(95 \% \mathrm{CI})$ does not overlap zero. The estimates relative to the plot factor were calculated using BAVH plot as reference level. trade-off between growth rate and reproductive success. We indeed showed that faster growing individuals have produced a larger number of surviving offspring, both through their female and male function. Similar conclusions were reached by studies that evaluated the relationship between cone crop size and radial growth in Norway spruce (Seifert and Müller-Starck 2009; Hacket-Pain et al. 2019). These authors discussed their results in the light of alternative hypotheses on Norway spruce mast seeding behaviour, and they concluded that 'resource switching' (i.e., resources are diverted from vegetative growth with a reduction of wood increment in years of high seed production; Kelly 1994) likely happens only during years of unfavourable resource assimilation. On the other hand, growth rate would not be affected when conditions were not limiting even with the additional costs of producing reproductive structures. Although our data did not allow us to track the reproductive costs at specific years or masting events, the positive relationship between growth rate and reproductive success found in our study clearly showed that, although resources might be switched depending on the intensity of reproduction, this had little impact on the lifetime growth rate of reproductively dominant trees. In fact, these individuals could have better compensated reproductive costs by increasing their resource intake and/or through other compensatory mechanisms (Tuomi et al. 1983; Obeso 2002). Indeed, the positive relationship found in our study between $\operatorname{Prev}_{\mathrm{T}}$ and reproductive success goes exactly in this direction, as discussed in the next section.

As for growth rate, age was rarely included as covariate of reproductive success in parentage-based studies. We found that age was significantly associated with both female and male reproductive success, but with substantial differences among sexes. In fact, the relationship was positive and linear for father trees, while it was hump-shaped for mother trees, as female reproductive success started to decrease around $\sim 160$ years. In red oaks, Moran and Clark (2012) reported a similar age-related trend for female reproductive success, showing that it declined beyond $\sim 100$ years. Even though sex allocation theory predicts that, in general, plants should allocate more to the female function with increasing age/size (Freeman et al. 1980; Charnov 1982; Lloyd and Bawa 1984; de Jong and Klinkhamer 1989), older/taller individuals tend to allocate more to the male function in wind-pollinated species (Burd and Allen 1988; Fox 1993). In fact, wind-mediated pollen dispersal becomes more effective for dominant trees, while the chance of seedling establishment in their neighbourhood likely decreases as competition with local offspring increases (Lloyd and Bawa 1984). Reproductive senescence 
associated to the female function might be alternatively interpreted as a consequence of an age-related reduction of the seed crop due to the higher costs of seed vs. pollen production (Sato 2004), although there is mixed evidence for such age-related decline of reproductive output in conifers (e.g., Silvertown et al. 2001; Viglas et al. 2013). Finally, another possibility to partially explain the humpshaped relationship between age and female reproductive success is that the estimates of reproductive success of the oldest trees were influenced by the demographic dynamics of the population (e.g., their progenies are now in the adult class and/or have been filtered out to a larger extent). However, it should be noted that the confidence interval of the relationship between age and reproductive success was large in the final part of the curve, as there were few spruces $>160$ years in our plots. However, studying age-related trends in natural populations inherently implies to deal with such heteroscedasticity issues.

\section{The influence of climate sensitivity to previous year temperature on reproductive success}

Among the dendrophenotypic variables that describe individual climate sensitivity, $\operatorname{Prev}_{\mathrm{T}}$ was the only one that was significantly and positively associated to female reproductive success. Considering that average $\operatorname{Prev}_{\mathrm{T}}$ was slightly negative, such positive relationship means that those trees that have responded less negatively to the mean temperature of the previous vegetative season have produced more offspring. Although Norway spruce has a very large amongsite variation in its responses to climate (Makinen et al. 2002; Lebourgeois 2007), an average negative climategrowth correlation with the mean temperature of the previous vegetative season has often been documented (e.g., Miina 2000; Makinen et al. 2002; Carrer et al. 2012). In boreal trees, such negative correlation can be partly explained by the fact that high temperatures during the latter part of the previous summer promote intense flowering during the following vegetative season (Tirén 1935; Lindgren et al. 1977; Pukkala et al. 2010) and that significant growth reduction can be associated to masting years (e.g., Chalupka et al. 1975; Pukkala 1987). However, it is essential to highlight that growth-climate correlations were generally calculated at the population level, thus preventing to depict the entire range of individual climatic responses (Carrer 2011). When such climatic responses were investigated at the individual level, a large inter-individual variation was found (Carrer 2011; Avanzi et al. 2019). Among this wide spectrum of climatic responses, our results pointed out that those mother trees that better handle potential growth limitations due to the temperature of the previous vegetative season were the most successful in terms of fitness. Keeping high growth rates despite potentially limiting conditions might represent a strategy to compensate reproductive costs, pursued by an increased resource intake or the mobilisation of stocked resources (Tuomi et al. 1983; Obeso 2002; Barringer et al. 2013).

\section{Dendrophenotypic traits showing no or inconsistent effect on reproductive success}

Although Norway spruce is characterised by a large amongsite variation in its responses to climate-related limiting factors (Levanič et al. 2009), several pieces of evidence showed that the temperature of the current vegetative season, as well as the water supply of the previous year, are relevant for radial growth dynamics (e.g., Büntgen et al. 2006; Lebourgeois 2007; Carrer et al. 2012; Kolár et al. 2017). We indeed found a slightly positive correlation between growth and both temperature of the current vegetative season $\left(\mathrm{Curr}_{\mathrm{T}}\right)$ and precipitation of the previous one $\left(\operatorname{Prev}_{\mathrm{P}}\right)$ at the population level. Nevertheless, neither $\operatorname{Curr}_{\mathrm{T}}$ nor $\operatorname{Prev}_{P}$ had a significant effect on individual reproductive success consistently across the two approaches used. Contrary to $\operatorname{Prev}_{\mathrm{T}}$, literature on the reproductive dynamics of Norway spruce did not highlighted functional links between these responses to climate and the reproductive output, and our results confirm that the most important climatic drivers of growth do not necessarily affect the reproductive cycle from cone production to the survival of progenies.

Besides evaluating the effect of seasonal responses to climate, this study also aimed to assess the relationship between individual fitness and growth responses to extreme climatic events. Recent association genetics studies investigated the relationships between potentially adaptive genetic variation and growth responses to extreme climatic events in conifers, raising the attention on such dendrophenotypic traits (Evans et al. 2018). A few candidate genes were found to be associated to growth responses to drought (Heer et al. 2018; Housset et al. 2018; TrujilloMoya et al. 2018). In particular, two candidate genes were found to be exclusively associated with resistance and resilience to the 1976 drought episode that heavily affected silver fir in Central Europe (Heer et al. 2018). In light of this evidence, we used growth responses to the 2003 drought episode, the only one encompassed by all the adult trees of our study, to describe individual capacity to cope with extreme climatic events. Our results showed that $\mathrm{Rt}_{2003}$, $\mathrm{Rc}_{2003}$ and $\mathrm{Rs}_{2003}$ were not associated with reproductive success consistently across the two approaches used, thus apparently indicating that trees that better coped with such intense drought episode did not have reproductive advantages. This might be partially explained by the fact that trees are generally little affected by episodic drought, as they use stored resources as a buffer against energy depletion in stressful years (Barringer et al. 2013). Nevertheless, a 
greater frequency of drought episodes is expected to reduce tree resilience by reducing the reserves they used to cope with such stressful episodes (Lloret et al. 2011). In this regard, our dataset offers limited opportunities due to the high frequency, in some of the study plots, of relatively young adult trees that could not have experienced multiple stressful events. A research designed to investigate the effect of recurrent stressful events should be necessarily focused on old growth forests or long-lived individuals growing in environmental limiting conditions.

\section{Final remarks and future directions}

Combining parentage analysis with the dendrophenotypic characterisation of putative parents has offered the unique opportunity to link forest trees' growth performances and their evolutionary gains. To our knowledge, this is the first attempt to apply this analytical framework with such a thorough and multidimensional phenotypic characterisation, comprising the dendrophenotypic traits deemed as most relevant to the potential adaptation of conifers to climate change (Housset et al. 2018). Obtaining direct measures of fitness is resource- and time-consuming (Younginger et al. 2017) and investigating their phenotypic determinants only provides idiosyncratic evidence if the study is not properly replicated. Gathering results on replicated sites is the only way to move from case-study evidence towards a generalisation at the species level. Here, we presented a detailed investigation of potential phenotypic determinants of the reproductive success of 518 trees in five Norway spruce natural populations. By embracing the change in perspective suggested by dendrochronological literature to switch from a classical population-based approach to a deep individual-based exploration of growth dynamics (Carrer 2011; Galván et al. 2014; Büntgen 2019) and recent indications suggesting to move beyond the search for single traits targeted by selection (Bontemps et al. 2017; Younginger et al. 2017), a large set of dendrophenotypic traits were tested against reproductive success. The main findings of our work coherently suggest that, regardless the number of reproductive seasons they have been through, Norway spruce individuals with the highest fitness were those keeping general high growth rates, in particular when temperature of the previous vegetative season might be limiting. The genetic and dendrochronological data used in our study are a convenient choice to carry out such a large scale investigation of the effect of growth traits on reproductive success. However, rapid technical advances will make feasible to get a detailed genomic and dendroanatomical characterisation of hundreds of trees. Combining genomic and high-throughput phenotypic data will allow to deepen our understanding of the functional link between the genotype and phenotype into an evolutionary perspective. Despite potential future refinements, we deem that the approach presented here will prove one of the most promising strategy to boost our knowledge on the processes underlying the transmission of genetic information across generations in forest trees.

\section{Data availability}

Genotypes, tree-ring-based phenotypic traits and spatial positions of each individual have been deposited at FigShare: https://doi.org/10.6084/m9.figshare.11845347.v1.

Acknowledgements This research is part of Camilla Avanzi's PhD within the Doctoral Programme in Evolutionary Biology and Ecology, Universities of Ferrara, Florence and Parma. This research was supported by the ERAnet BiodivERsA project 'TipTree' (ANR-12-EBID0003), the German Federal Ministry of Education and Research (Grant 01LC1202A) and the Italian MIUR project 'Biodiversitalia' (RBAP10A2T4). Special thanks are due to the personnel of Ufficio per la Biodiversità of Pistoia, the Italian State Forest Service of Abetone (PT) and the Bavarian Forest National Park for logistic support to field activities. We also thank V. Gallucci, M. Garbarino, C. Leonarduzzi, I. Spanu, D. Castagneri, S. Lorch and M. Weller, L. Hellmann, D. Galván Candela and R. Ochoa Pereira for help during field work, V. Gallucci, S. Lorch, M. Weller, A. Verstege for processing dendrochronological samples, and I. Spanu and C. Boggi for technical assistance during lab work. Finally, we would like to thank S. OddouMuratorio and M. Carrer for valuable feedback on an earlier version of the manuscript, and three anonymous reviewers for their helpful comments and suggestions.

\section{Compliance with ethical standards}

Conflict of interest The authors declare that they have no conflict of interest.

Publisher's note Springer Nature remains neutral with regard to jurisdictional claims in published maps and institutional affiliations.

\section{References}

Aho K, Derryberry D, Peterson T (2014) Model selection for ecologists: the worldviews of AIC and BIC. Ecology 95:631-636

Avanzi C, Piermattei A, Piotti A, Büntgen U, Heer K, Opgenoorth L et al. (2019) Disentangling the effects of spatial proximity and genetic similarity on individual growth performances in Norway spruce natural populations. Sci Total Environ 650:493-504

Babushkina EA, Vaganov EA, Grachev AM, Oreshkova NV, Belokopytova LV, Kostyakova TV et al. (2016) The effect of individual genetic heterozygosity on general homeostasis, heterosis and resilience in Siberian larch (Larix sibirica Ledeb.) using dendrochronology and microsatellite loci genotyping. Dendrochronologia 38:26-37

Barringer BC, Koenig WD, Knops JMH (2013) Interrelationships among life-history traits in three California oaks. Oecologia 171:129-139

Barton K (2018) MuMIn: Multi-Model Inference. R package version 1.40.4. https://CRAN.R-project.org/package $=$ MuMIn

Bernasconi G (2003) Seed paternity in flowering plants: an evolutionary perspective. Perspect Plant Ecol Evol Syst 6:149-158 
Biondi F, Qeadan F (2008) A theory-driven approach to tree-ring standardization: defining the biological trend from expected basal area increment. Tree-Ring Res 64:81-96

Black BA, Colbert JJ, Pederson N (2008) Relationships between radial growth rates and lifespan within North American tree species. Ecoscience 15:349-357

Bontemps A, Davi H, Lefèvre F, Rozenberg P, Oddou-Muratorio S (2017) How do functional traits syndromes covary with growth and reproductive performance in a water-stressed population of Fagus sylvatica? Oikos 126:1472-1483

Bunn AG (2008) A dendrochronology program library in R (dplR). Dendrochronologia 26:115-124

Büntgen U (2019) Re-thinking the boundaries of dendrochronology. Dendrochronologia 53:1-4

Büntgen U, Frank DC, Schmidhalter M, Neuwirth B, Seifert M, Esper J (2006) Growth/climate response shift in a long subalpine spruce chronology. Trees 20:99-110

Burczyk J, Adams WT, Birkes DS, Chybicki IJ (2006) Using gegnetic markers to directly estimate gene flow and reproductive success parameters in plants on the basis of naturally regenerated seedlings. Genetics 173:363-372

Burd M, Allen TFH (1988) Sexual allocation strategy in windpollinated plants. Evolution 42:403-407

Burnham KP, Anderson DR (2002) Model selection and multimodel inference: a practical information-theoretic approach. Springer Verlag, Berlin

Carrer M, von Arx G, Castagneri D, Petit G (2015) Distilling allometric and environmental information from time series of conduit size: the standardization issue and its relationship to tree hydraulic architecture. Tree Physiol 35:27-33

Carrer M, Motta R, Nola P (2012) Significant mean and extreme climate sensitivity of Norway spruce and silver fir at mid-elevation mesic sites in the Alps. PLoS ONE 7:e50755

Carrer M (2011) Individualistic and time-varying tree-ring growth to climate sensitivity. PLoS ONE 6:e22813

Chalupka W, Giertych M, Krolikowski Z (1975) The effect of cone crops on growth of Norway spruce (Picea abies (L.) Karst.). Arbor Kornickie 20:201-212

Charnov EL (1982) The theory of sex allocation. Princeton University Press, New Jersey

Chen Z-Q, Baison J, Pan J, Karlsson B, Andersson B, Westin J et al. (2018) Accuracy of genomic selection for growth and wood quality traits in two control-pollinated progeny trials using exome capture as the genotyping platform in Norway spruce. BMC Genomics 19:946

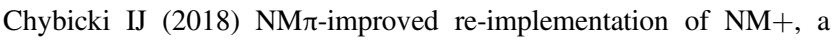
software for estimating gene dispersal and mating patterns. Mol Ecol Resour 18:159-168

Chybicki IJ, Oleksa A (2018) Seed and pollen gene dispersal in Taxus baccata, a dioecious conifer in the face of strong population fragmentation. Ann Bot 122:409-421

Chybicki IJ, Burczyk J (2010) Realized gene flow within mixed stands of Quercus robur L. and Q. petraea (Matt.) L. revealed at the stage of naturally established seedling. Mol Ecol 19:2137-2151

Cook ER, Kairiukstis LA (1990) Methods of dendrochronology: applications in the environmental sciences. Kluwer Academic Publishers, Dondrecht

Davi H, Cailleret M, Restoux G, Amm A, Pichot C, Fady B (2016) Disentangling the factors driving tree reproduction. Ecosphere $7: 1-16$

Eis S, Garman EH, Ebell LF (1965) Relation between cone production and diameter increment of Douglas fir (Pseudotsuga menziesii (mirb.) Franco), grand fir (Abies grandis (dougl.) Lindl.), and western white pine (Pinus monticola Dougl.). Can J Bot 43:1553-1559
Eklund B (1957) Annual ring variation of spruce in central Norrland and its relation to climate. Medd Statens Skogsforskningsinst 47:1-63

Evans MEK, Gugger PF, Lynch AM, Guiterman CH, Fowler JC, Klesse S et al. (2018) Dendroecology meets genomics in the common garden: new insights into climate adaptation. N. Phytol 218:401-403

Fink AH, Brucher T, Kruger A, Leckebusch GC, Pinto JG, Ulbrich U (2004) The 2003 European summer heat waves and droughtsynoptic diagnosis and impact. Weather 59:209-216

Fluch S, Burg A, Kopecky D, Homolka A, Spiess N, Vendramin GG (2011) Characterization of variable EST SSR markers for Norway spruce (Picea abies L.). BMC Res Notes 4:401

Fonti P, Von Arx G, García-González I, Eilmann B, Sass-Klaassen U, Gärtner H et al. (2010) Studying global change through investigation of the plastic responses of xylem anatomy in tree rings. New Phytol 185:42-53

Fox JF (1993) Size and sex allocation in monoecious woody plants. Oecologia 94:110-113

Fox J, Weisberg S (2011) An R Companion to Applied Regression. Sage, Thousand Oaks

Freeman DC, Harper KT, Charnov EL (1980) Sex change in plants: old and new observations and new hypotheses. Oecologia 47:222-232

Galván JD, Camarero JJ, Gutiérrez E (2014) Seeing the trees for the forest: drivers of individual growth responses to climate in Pinus uncinata mountain forests. J Ecol 102:1244-1257

Gerber S, Chabrier P, Kremer A (2003) FAMOZ: A software for parentage analysis using dominant, codominant and uniparentally inherited markers. Mol Ecol Notes 3:479-481

Gerzabek G, Oddou-Muratorio S, Hampe A (2017) Temporal change and determinants of maternal reproductive success in an expanding oak forest stand. J Ecol 105:39-48

González-Martínez SC, Burczyk J, Nathan R, Nanos N, Gil L, Alía R (2006) Effective gene dispersal and female reproductive success in Mediterranean maritime pine (Pinus pinaster Aiton). Mol Ecol 15:4577-4588

Hacket-Pain A, Ascoli D, Berretti R, Mencuccini M, Motta R, Nola P et al. (2019) Temperature and masting control Norway spruce growth, but with high individual tree variability. Ecol Manag 438:142-150

Hamann A, Wang T, Spittlehouse DL, Murdock TQ (2013) A comprehensive, high-resolution database of historical and projected climate surfaces for western north America. Bull Am Meteorol Soc 94:1307-1309

Hannrup B, Cahalan C, Chantre G, Grabner M, Karlsson B, Le Bayon I et al. (2004) Genetic parameters of growth and wood quality traits in Picea abies. Scand J Res 19:14-29

Harris I, Jones PD, Osborn TJ, Lister DH (2014) Updated highresolution grids of monthly climatic observations-the CRU TS3.10 Dataset. Int J Climatol 34:623-642

Hartig F (2019) DHARMa: Residual diagnostics for hierarchical regression models. $\mathrm{R}$ package version 0.2.6. https://CRAN.Rproject.org/package $=$ DHARMa

Heer K, Behringer D, Piermattei A, Bässler C, Brandl R, Fady B et al. (2018) Linking dendroecology and association genetics in natural populations: stress responses archived in tree rings associate with SNP genotypes in silver fir (Abies alba Mill.). Mol Ecol 27:1428-1438

Hember RA, Kurz WA, Metsaranta JM (2015) Ideas and perspectives: use of tree-ring width as an indicator of tree growth. Biogeosci Discuss 12:8341-8352

Housset JM, Nadeau S, Isabel N, Depardieu C, Duchesne I, Lenz P et al. (2018) Tree rings provide a new class of phenotypes for genetic associations that foster insights into adaptation of conifers to climate change. New Phytol 218:630-645 
Housset JM, Carcaillet C, Girardin MP, Xu H, Tremblay F, Bergeron $\mathrm{Y}$ (2016) In situ comparison of tree-ring responses to climate and population genetics: the need to control for local climate and site variables. Front Ecol Evol 4:123

Jones AG, Small CM, Paczolt KA, Ratterman NL (2010) A practical guide to methods of parentage analysis. Mol Ecol Resour 10:6-30

de Jong TJ, Klinkhamer PG (1989) Size-dependency of sex-allocation in hermaphroditic, monocarpic plants. Funct Ecol 3:201-206

Kameyama Y, Isagi Y, Nakagoshi N (2001) Patterns and levels of gene flow in Rhododendron metternichii var. hondoense revealed by microsatellite analysis. Mol Ecol 10:205-216

Kaufman S, Smouse P, Alvarez-Buylla E (1998) Pollen-mediated gene flow and differential male reproductive success in a tropical pioneer tree, Cecropia obtusifolia Bertol.(Moraceae): a paternity analysis. Heredity 81:164-173

Kelly D (1994) The evolutionary ecology of mast seeding. Trends Ecol Evol 9:465-470

King GM, Gugerli F, Fonti P, Frank DC (2013) Tree growth response along an elevational gradient: climate or genetics? Oecologia 173:1587-1600

Klein EK, Desassis N, Oddou-Muratorio S (2008) Pollen flow in the wildservice tree, Sorbus torminalis (L.) Crantz. IV. Whole interindividual variance of male fecundity estimated jointly with the dispersal kernel. Mol Ecol 17:3323-3336

Koláŕ T, Čermák P, Trnka M, Žid T, Rybníček M (2017) Temporal changes in the climate sensitivity of Norway spruce and European beech along an elevation gradient in Central Europe. Agric Meteorol 239:24-33

Latutrie M, Mérian P, Picq S, Bergeron Y, Tremblay F (2015) The effects of genetic diversity, climate and defoliation events on trembling aspen growth performance across Canada. Tree Genet Genomes 11:96

Lebourgeois F (2007) Climatic signal in annual growth variation of silver fir (Abies alba Mill.) and spruce (Picea abies Karst.) from the French Permanent Plot Network (RENECOFOR). Ann Sci 64:333-343

Leonarduzzi C, Piotti A, Spanu I, Vendramin GG (2016) Effective gene flow in a historically fragmented area at the southern edge of silver fir (Abies alba Mill.) distribution. Tree Genet Genomes 12:95

Levanič T, Gričar J, Gagen M, Jalkanen R, Loader NJ, McCarroll D et al. (2009) The climate sensitivity of Norway spruce [Picea abies (L.) Karst.] in the southeastern European Alps. Trees 23:169-180

Lind BM, Menon M, Bolte CE, Faske TM, Eckert AJ (2018) The genomics of local adaptation in trees: are we out of the woods yet? Tree Genet Genomes 14:29

Lindgren K, Ekberg I, Eriksson G (1977) External factors influencing female flowering in Picea abies (L.) Karst. Studia Forestalia Suecica 142, Skogshögskolan, Stockholm

Lloret F, Keeling EG, Sala A (2011) Components of tree resilience: effects of successive low-growth episodes in old ponderosa pine forests. Oikos 120:1909-1920

Lloyd DG, Bawa KS (1984) Modification of the gender of seed plants in varying conditions. Evol Biol 17:255-339

Makinen H, Nojd P, Kahle H, Neumann U, Tveite B, Mielikainen K et al. (2002) Radial growth variation of Norway spruce (Picea abies (L.) Karst.) across latitudinal and altitudinal gradients in central and northern Europe. Ecol Manag 171:243-259

Martinez Meier AG, Sanchez L, Salda G, Pastorino MJM, Gautry J-Y, Gallo LA et al. (2008) Genetic control of the tree-ring response of Douglas-fir (Pseudotsuga menziesii (Mirb.) Franco) to the 2003 drought and heat-wave in France. Ann Sci 65:102-102

Miina J (2000) Dependence of tree-ring, earlywood and latewood indices of Scots pine and Norway spruce on climatic factors in eastern Finland. Ecol Model 132:259-273
Moran EV, Clark JS (2012) Causes and consequences of unequal seedling production in forest trees: a case study in red oaks. Ecology 93:1082-1094

Morgan MT, Conner JK (2001) Using genetic markers to directly estimate male selection gradients. Evolution 55:272-281

Obeso JR (2002) The costs of reproduction in plants. N. Phyt $155: 321-348$

Oddou-Muratorio S, Gauzere J, Bontemps A, Rey J-F, Klein EK (2018a) Tree, sex and size: ecological determinants of male vs. female fecundity in three Fagus sylvatica stands. Mol Ecol 27:3131-3145

Oddou-Muratorio S, Petit C, Journé V, Lingrand M, Magdalou JA, Hurson C, et al. (2018b) Crown defoliation decreases reproduction and wood growth in a marginal European beech population. https://doi.org/10.1101/474874

Oddou-Muratorio S, Klein EK (2008) Comparing direct vs. indirect estimates of gene flow within a population of a scattered tree species. Mol Ecol 17:2743-2754

Oddou-Muratorio S, Klein EK, Austerlitz F (2005) Pollen flow in the wildservice tree, Sorbus torminalis (L.) Crantz. II. Pollen dispersal and heterogeneity in mating success inferred from parentoffspring analysis. Mol Ecol 14:4441-4452

Petit RJ, Hampe A (2006) Some evolutionary consequences of being a tree. Annu Rev Ecol Evol Syst 37:187-214

Pfeiffer A, Olivieri A, Morgante M (1997) Identification and characterization of microsatellites in Norway spruce (Picea abies K.). Genome 40:411-419

Piotti A, Leonardi S, Piovani P, Scalfi M, Menozzi P (2009) Spruce colonization at treeline: where do those seeds come from? Heredity 103:136-145

Piotti A, Leonardi S, Buiteveld J, Geburek T, Gerber S, Kramer K et al. (2012) Comparison of pollen gene flow among four European beech (Fagus sylvatica L.) populations characterized by different management and evolutionary histories. Heredity 108:222-231

Pukkala T, Hokkanen T, Nikkanen T (2010) Prediction models for the annual seed crop of Norway spruce and Scots pine in Finland. Silva Fenn 44:629-642

Pukkala T (1987) Siementuotannon vaikutus kuusen ja männyn vuotuiseen kasvuun (Effect of seed production on the annual growth of Picea abies and Pinus sylvestris). Silva Fenn 21:145-158

R Core Team (2019) R: a language and environment for statistical computing. R Foundation for Statistical Computing, Vienna, Austria, https://www.R-project.org/

Rungis D, Bérubé Y, Zhang J, Ralph S, Ritland CE, Ellis BE et al. (2004) Robust simple sequence repeat markers for spruce (Picea spp.) from expressed sequence tags. Theor Appl Genet 109:1283-1294

Sato T (2004) Size-dependent sex allocation in hermaphroditic plants: the effects of resource pool and self-incompatibility. J Theor Biol 227:265-275

Schnabel A, Nason JD, Hamrick JL (1998) Understanding the population genetic structure of Gleditsia triacanthos L.: seed dispersal and variation in female reproductive success. Mol Ecol 7:819-832

Schoen DJ, Stewart SC (1986) Variation in male reproductive investment and male reproductive success in white spruce. Evolution 40:1109-1120

Scotti I, Magni F, Paglia G, Morgante M (2002) Trinucleotide microsatellites in Norway spruce (Picea abies): their features and the development of molecular markers. Theor Appl Genet 106:40-50

Seifert T, Müller-Starck G (2009) Impacts of fructification on biomass production and correlated genetic effects in Norway spruce (Picea abies [L.] Karst.). Eur J Res 128:155-169

Silvertown J, Franco M, Perez-Ishiwara R (2001) Evolution of senescence in iteroparous perennial plants. Evol Ecol Res 3:393-412

Smouse PE, Sork VL (2004) Measuring pollen flow in forest trees: an exposition of alternative approaches. Ecol Manag 197:21-38 
Smouse PE, Meagher TR, Lobak CJ (1999) Parentage analysis in Chaemeclirium luteum (L.) Gray (Liliaceae): why do some males have higher contributions? J Evol Biol 12:1069-1077

Steffenrem A, Kvaalen H, Høibø OA, Edvardsen ØM, Skrøppa T (2009) Genetic variation of wood quality traits and relationships with growth in Picea abies. Scand J Res 24:15-27

Tirén L (1935) Om granens kottsättning, des periodicitet och samband med temperature och nederbörd. Medd från Statens Skogsforskningsinstitut 28:413-518

Trujillo-Moya C, George J-P, Fluch S, Geburek T, Grabner M, Karanitsch-Ackerl S et al. (2018) Drought sensitivity of Norway spruce at the species' warmest fringe: quantitative and molecular analysis reveals high genetic variation among and within provenances. Genes|Genomes|Genet 8:1225-1245

Tuomi J, Hakala T, Haukioja E (1983) Alternative concepts of reproductive efforts, costs of reproduction and selection in life hystory evolution. Am Zool 23:25-34 van der Maaten-Theunissen M, Kahle H-P, van der Maaten E (2013) Drought sensitivity of Norway spruce is higher than that of silver fir along an altitudinal gradient in southwestern Germany. Ann Sci 70:185-193

Venables WN, Ripley BD (2002) Modern applied statitics with S. Springer Ferlag, NewYork, NY

Vendramin GG, Lelli L, Rossi P, Morgante M (1996) A set of primers for the amplification of 20 chloroplast microsatellites in Pinaceae. Mol Ecol 5:595-598

Viglas JN, Brown CD, Johnstone JF (2013) Age and size effects on seed productivity of northern black spruce. Can J Res 43:534-543

Younginger BS, Sirová D, Cruzan MB, Ballhorn DJ (2017) Is biomass a reliable estimate of plant fitness? Appl Plant Sci 5:1600094

Zuur AF, Ieno EN, Elphick CS (2010) A protocol for data exploration to avoid common statistical problems. Methods Ecol Evol 1:3-14 